\title{
Determination of the Response Amplitude Operator(s) of an FPSO
}

\author{
Imabibo Ibinabo, Daniel T. Tamunodukobipi ${ }^{1,2}$ \\ ${ }^{1}$ Department of Marine Engineering, Rivers State University, Port Harcourt, Nigeria \\ ${ }^{2}$ Centre of Excellence, Rivers State University, Port Harcourt, Nigeria \\ Email: anietieco@gmail.com
}

How to cite this paper: Ibinabo, I. and Tamunodukobipi, D.T. (2019) Determination of the Response Amplitude Operator(s) of an FPSO. Engineering, 11, 541-556. https://doi.org/10.4236/eng.2019.119038

Received: May 15, 2019

Accepted: September 7, 2019

Published: September 10, 2019

Copyright (c) 2019 by author(s) and Scientific Research Publishing Inc. This work is licensed under the Creative Commons Attribution International License (CC BY 4.0).

http://creativecommons.org/licenses/by/4.0/

\begin{abstract}
The driving necessities of cost reduction and the need to develop fields at ever increasing water depths have led to the use of floating structures. Among these structures are the Floating Production Storage and Offloading (FPSO) units whose motion analysis is considered in this paper. In actual environmental condition, it is required to accurately determine or predict large amplitude motion of the FPSO before any offshore operation. This paper seeks to present a detailed method of computing the Response Amplitude Operator(s) (RAOs) for the six (6) degrees of freedom using ANSYS AQWA. The results indicate for Heave motion a tendency for the heave peak value to move slightly higher dimensionless encounter-frequency as the wave moves from Head sea to Beam sea direction. A MATLAB source code was developed to validate the result for heave motion at head sea. Although a small difference in predicted heave motion occurred, it is pertinent to note that the comparisons between results generated in the MATLAB program and ANSYS AQWA demonstrate generally good agreement, and the roll response of the FPSO is noted to be critical.
\end{abstract}

\section{Keywords}

Response Amplitude Operator(s), Floating Production Storage and Offloading Unit, ANSYS AQWA, MATLAB, Simplified Method

\section{Introduction}

Floating Production Storage and Offloading (FPSO) units as the name implies are used in the offshore industry for the storage and processing of oil and gas. Her storage capacity is large with enough deck area space to accommodate the production equipment as shown in Figure 1. This floating structure has the capability to produce, store and offload the oil, but does not have the capability to 


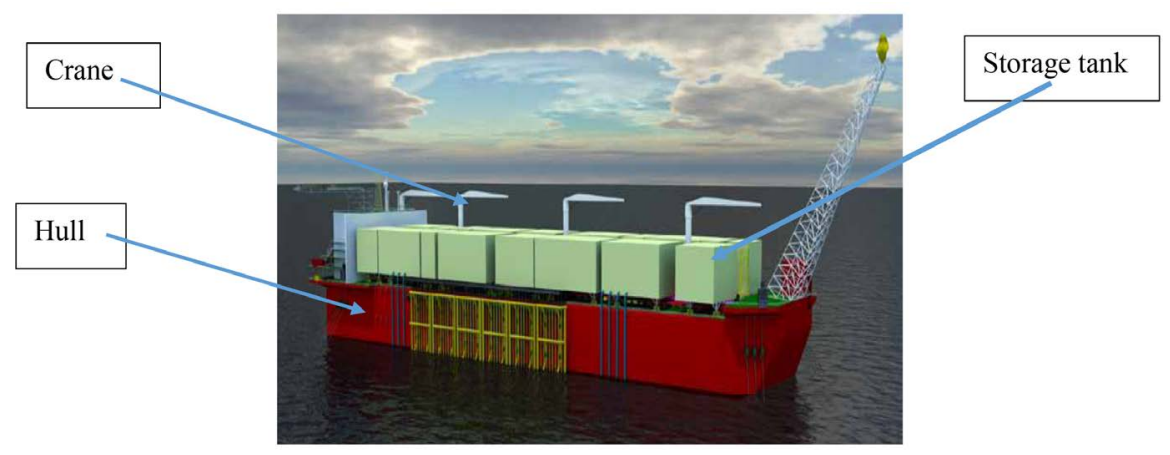

Figure 1. FPSO model.

drill. In actual condition, the FPSO will respond to environmental loads due to wind, waves, and currents, which make the FPSO be on the motion. The interest in the FPSO motion characteristics stems from the need to predict and control large-amplitude motions that can reduce the operational level and affects the performance of the process.

A generic procedure for predicting the FPSO motions is to have an input-output system, where the ship response is predicted from the input, usually, of an irregular seaway. Such a system is based on a transfer function, also known as "response amplitude operator" (RAO). The validity of this operator is based on the assumption of linearity between the wave excitation and the system's response [1]. As such, the RAO(s) is usually determined in a regular seaway for various wave frequencies and directions either analytical, experimentally, or via numerical simulations to predict the ship motion response, such as the Surge, Sway, Heave, Roll, Pitch and Yaw motion as described in Figure 2.

Hence, the RAOs serve to linearly relate the frequency components of one or more of the ship responses to the same components in the wave spectrum and describe how the response of the FPSO varies with the frequency.

\section{Methods of Analyzing Hydrodynamic Response}

Hydrodynamic responses of a floating structure are analyzed using the best available methods. The common method is by conducting a model test in an ocean basin, which gives more accurate prediction of the ship behavior. Over time with the introduction of computer programs and computing technology, numerical simulation became another method used to analyze the motion responses of ocean structures in waves. The role of numerical simulations in the engineering design process is constantly increasing since the virtual test is conducted in controlled environmental conditions and the amount of information available is in orders of magnitude higher than any complex physical testing. The increasing availability of powerful computational resources has recently attracted a large amount of research in the field of the simulation of waves and wave-structures interaction processes.

Computer programs for predicting the motion response of a floating structure are developed based on potential flow theory. According to [2], a popular tool 

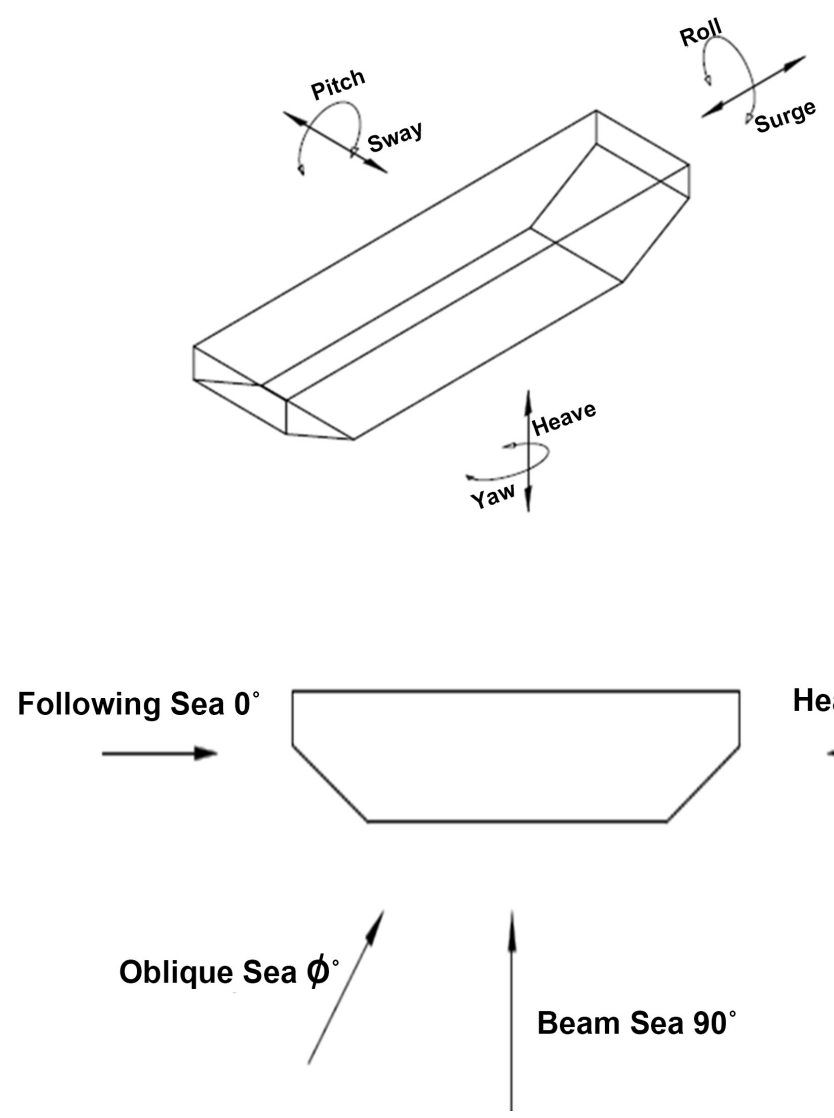

Head Sea $180^{\circ}$

Figure 2. FPSO response modes and wave direction.

for computing RAOs of offshore structure is ANSYS AQWA, which implements a three-dimensional panel code to compute the linear wave forcing and motion characteristics of offshore structures in the frequency domain. Other predictors of motion responses are for time domain [3], strip theory [4], and 3-D frequency domain [3]. Most of the sevirtual tools are based on different theories, and most often their predictions have some discrepancies. These seeming in consistencies in numerical predictors [5] are not due to the hydrodynamic theory applied, but due to over-simplifying assumptions during modeling. Nonetheless, numerical simulation is still used independently or in conjunction with veritable test data to characterize most engineering systems.

\section{Hydrodynamic Analysis}

\subsection{FPSO Characteristics}

The FPSO surface geometry and mass characteristics are input to ANSYS AQWA. These parameters are given in Table 1.

\subsection{FPSO Loading Condition}

Table 2 gives the loading conditions for the FPSO. Note that the RAOs are obtained for different loading (draft) condition. However, the present analysis considers the RAOs only for the full loading conditions: 
Table 1. FPSO geometric particulars.

\begin{tabular}{ccc}
\hline FPSO Particulars & Parameters & Unit \\
\hline Length over all & 280.00 & $(\mathrm{~m})$ \\
Length between perpendicular & 280.00 & $(\mathrm{~m})$ \\
Breadth (moulded) & 59.00 & $(\mathrm{~m})$ \\
Depth at side (moulded) & 31.00 & $(\mathrm{~m})$ \\
Depth at centerline (moulded) & 31.50 & $(\mathrm{~m})$ \\
ICLL Tropical draft & 25.8 & $(\mathrm{~m})$ \\
Midship position (forward from AP) & 140 & $(\mathrm{~m})$ \\
Type of freeboard & Type “A” of ICLL 1966 (Tropical) & \\
Type of ship & FPSO Unit & \\
\hline
\end{tabular}

Table 2. Loading conditions of the FPSO.

\begin{tabular}{|c|c|c|c|c|c|c|c|c|}
\hline LCOND & CASE & DISP & $\mathrm{T}$ & TR & HEEL & XCG & YCG & ZCG \\
\hline & & {$[t]$} & [m] & $\mathbf{M}$ & [deg] & [m] & [m] & {$[\mathrm{m}]$} \\
\hline COND01 & Full Load Operating Future FC & 358667.0 & 23.03 & -4.226 & 0.0 & 145.75 & 0.0 & 18.2 \\
\hline COND02 & Full Load Operating Future EC & 355044.5 & 22.806 & -3.06 & 0.0 & 144.62 & 0.0 & 18.13 \\
\hline COND03 & Ballast Operating Future FC & 145690.5 & 9.943 & -4.41 & 0.0 & 155.28 & 0.0 & 22.29 \\
\hline CONDO4 & Ballast Operating Future EC & 142068.0 & 7.716 & -3.047 & 0.0 & 152.71 & 0.0 & 22.22 \\
\hline COND05 & $\begin{array}{c}\text { Intermediate Load } \\
\text { Operating Future FC }\end{array}$ & 241479.0 & 15.916 & -4.214 & 0.0 & 148.85 & 0.0 & 19.32 \\
\hline COND06 & $\begin{array}{c}\text { Intermediate Load } \\
\text { Operating Future EC }\end{array}$ & 237856.5 & 15.691 & -2.965 & 0.0 & 147.22 & 0.0 & 19.24 \\
\hline
\end{tabular}

- Masses and lightweight elements are treated as box-shaped loads;

- The ship is assumed to be on even keel in the calculation of the products of inertia;

- Moments of inertia and radii of gyration are taken with respect to the CG of the loaded ship.

\subsection{Analysis Flow}

The analysis to determine the response behavior of the FPSO begins with modeling of the FPSO body hull. In general, the body surface geometry and mass distribution of the FPSO model are first described using a panel model, and are followed by the description of the environment, as shown in Figure 3. The FPSO has been modelled accurately using the design modeler in the ANSYS workbench [6].

\subsection{Coordinate System Definition}

Figure 4 presents the Cartesian coordinate system (X, Y, Z) defining the space coordinate system. It is fixed relative to the undisturbed positions of the free 


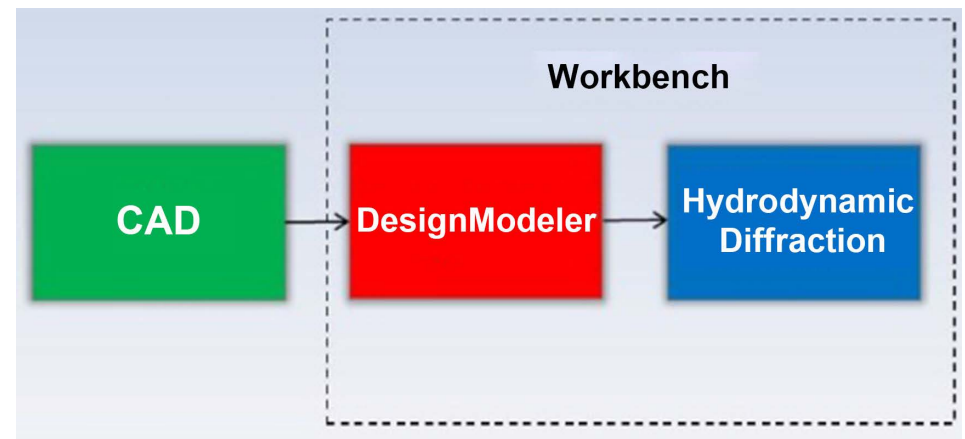

Figure 3. Schematic of the ANSYS AQWA workbench.

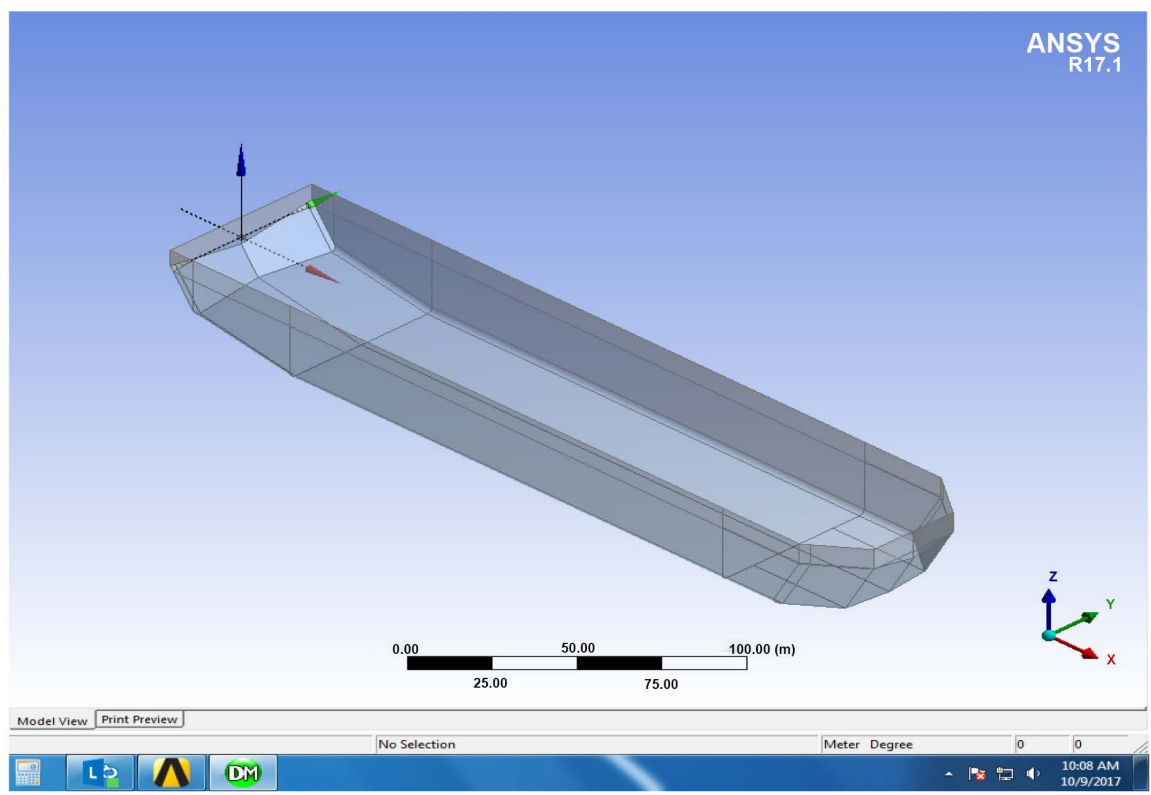

Figure 4. ANSYS AQWA workbench coordinate system.

surface, with the z-axis positive upwards. These coordinates are used to define the body geometry, motions, forces and other hydrodynamic quantities evaluated by ANSYS AQWA. The system of axes for hydrodynamic analysis for the FPSO RAOs (i.e. Coordinate of local positions) is as follows:

- $\mathrm{X}$-axis is positive towards bow from aft perpendicular (AP-frame 0 ).

- Y-axis is positive towards portside from ship centerline (CL).

- Z-axis is positive upwards from ship base line (BL).

In ANSYS AQWA, the thickness of the model is $0 \mathrm{~m}$ and it is sliced through the waterline (draft). The origin of the global coordinate is located at LCG in $\mathrm{X}$-direction, $\mathrm{CL}$ in $\mathrm{Y}$-direction and the distance of $\mathrm{KG}$ from the water surface in Z-direction. Consequently, all the hydrodynamic quantities are evaluated at the center of gravity of the vessel in ANSYS AQWA. The phase is defined relative to the phase of an incident wave at the origin of the global coordinates system in $\mathrm{X}$, $\mathrm{Y}$ and the free surface in $\mathrm{Z}$. The radiation and diffraction velocity potentials on the body wetted surface are determined from the solution of an integral equation obtained by using Green's theorem with the free-surface source-potential as the 
Green function. All of the quantities, like the exciting forces, motions, hydrodynamic pressure and field velocity induced by an incident wave, are defined relative to $\mathrm{X}=\mathrm{Y}=0$ in the global coordinate of ANSYS AQWA and $\mathrm{Z}=0$ which is actually located at KG level and may be located above or below the free surface.

\subsection{Input Data Tree in ANSYS AQWA}

Figure 5 and Figure 6 show the graphical interface for AQWA analysis platform. The interface has a number of key areas, but it is tree driven. The tree and the details are used to define the modelling requirements for the FPSO. Depending on the selection in the tree, a detailed pane, normally located below the tree shows the details of the selected object.

The maximum diagonal length of any element to be model is first ascertained. Since the diagonal length of panel mesh is influenced by the maximum allowed frequency, then it should be less than 1/7 of the smallest wave length of the highest frequency analyzed. Now, considering wave length associated to a period of $4 \mathrm{~s}$, this criterion leads to a maximum diagonal length slightly bigger than 4 $\mathrm{m}$. The wave length for $4 \mathrm{~s}$ equals:

$$
L=\frac{g}{2 \pi} T^{2} \tanh (k d)
$$

where: $g$-gravity accelerationg;

$$
\begin{aligned}
& T \text { - waveperiod }=(4 \mathrm{~s}) ; \\
& d \text {-waterdepth }=(1000 \mathrm{~m}) ; \\
& k \text {-wavenumbers }=\frac{2 \pi}{L} . \\
& \qquad L=\frac{g}{2 \pi} T^{2} \tanh \left(\frac{2 \pi}{L} d\right)=24.98 \mathrm{~m}
\end{aligned}
$$

In this study the maximum mesh size is $3.5 \mathrm{~m}$ : which leads to $3.5 \mathrm{~m} \times 7=24.5$ $\mathrm{m}$. The mesh size complies with the criterion since the maximum diagonal length of the mesh is slightly smaller than $4 \mathrm{~m}$ as shown in Figure 7.

Mass properties have to be set. The data are put to point mass and point buoyancy. These characteristics are estimated in CAD. The mass properties of the FPSO are given in Table 3. The geometry of the FPSO hull has been described by a panel model. The ship characteristics in harmonic waves are determined by ANSYS AQWA based on a 3D diffraction program. Linear motion

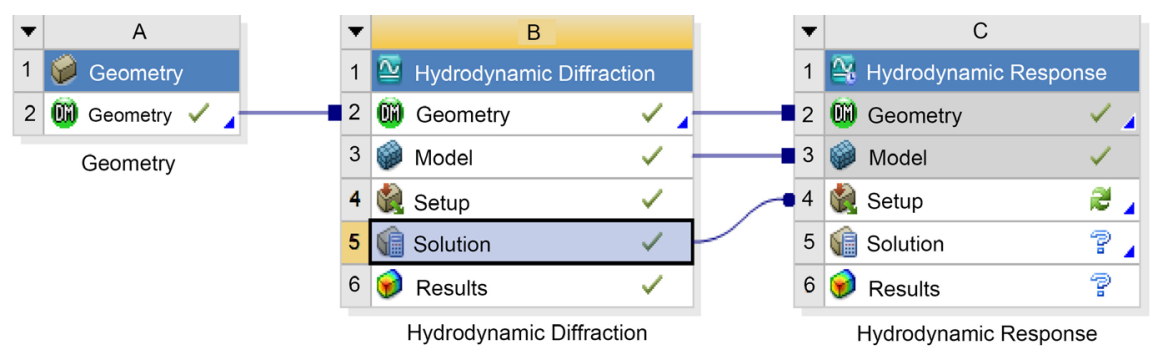

Figure 5. Block-scheme of ANSYS hydrodynamic analysis interface. 


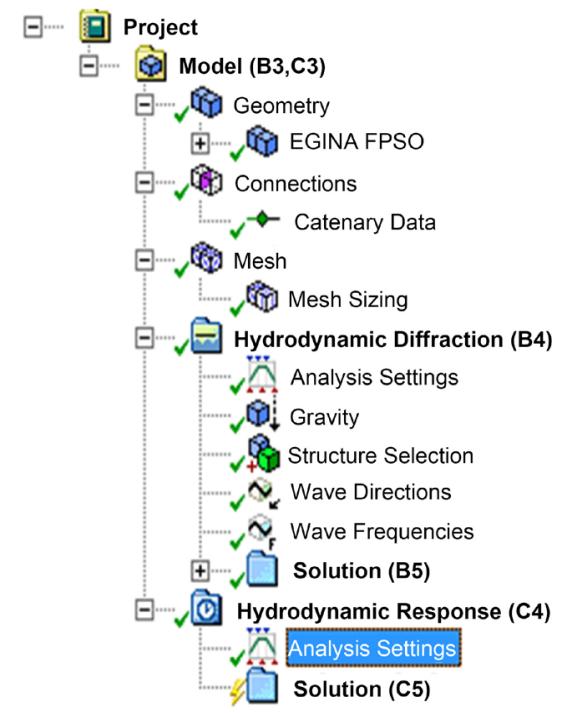

Figure 6. AQWA solver tree.

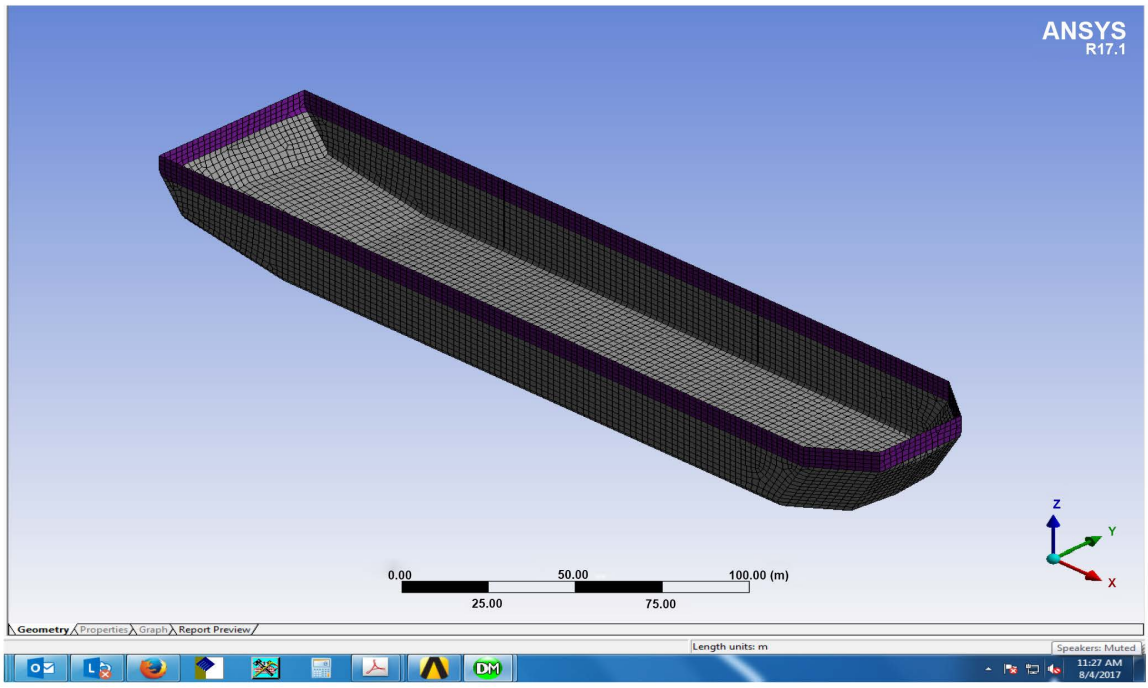

Figure 7. Mesh shape of FPSO SHOWING the top and bottom of the hull.

coefficients (RAOs) and resistance coefficients (added mass and damping coefficients) are determined and stored in a hydrodynamic data base. The analysis is performed with frequency and directional discretization. The motion and resistance coefficients are determined in six (6) degrees of freedom and for a range of wave frequencies and wave directions. This information is stored in a ship characteristics data base that is subsequently applied for the time domain analysis.

\subsection{Environmental Conditions for the Analysis}

For ANSYS AQWA computation, no forward speed effect is taken into account, the waves considered to compute the RAOs are in the range of periods $[1.0 \mathrm{~s}$ to $49.9 \mathrm{~s}$ ] with a step of $1.0 \mathrm{~s}$, except near the roll natural period. A range of wave frequencies is considered in the calculation of the RAOs with wave headings in 
Table 3. Mass properties of floating production storage offloading unit.

\begin{tabular}{ccc}
\hline Particulars & Parameters & Units \\
\hline LOA & 280.00 & $(\mathrm{~m})$ \\
LBP & 280.00 & $(\mathrm{~m})$ \\
B & 59.00 & $(\mathrm{~m})$ \\
D & 31.50 & $(\mathrm{~m})$ \\
Draft & 23.03 & $(\mathrm{~m})$ \\
Xg & 145.75 & $(\mathrm{~m})$ \\
Yg & 0 & $(\mathrm{~m})$ \\
Zg & 18.20 & $(\mathrm{~m})$ \\
Mass & 358667.0 & $(\mathrm{~kg})$ \\
Kxx & 17.6323 & $(\mathrm{~N} / \mathrm{m})$ \\
Kyy & 80.9484 & $(\mathrm{~N} / \mathrm{m})$ \\
Kzz & 80.9484 & $(\mathrm{~N} / \mathrm{m})$ \\
\hline
\end{tabular}

increments of 30 degrees from following seas (0 degrees) to head seas (180 degrees). Figure 8 defines the OXY plane of the fixed reference axes as being the directions which they travel along. The information received by ANSYS AQWA to define the body characteristics is output for validating the MATLAB source code.

\subsection{Simplified Method of Computing Heave Response Amplitude Operator (RAO)}

The dynamic pressure and acceleration of the added mass of water causing Heave motion at the bottom of the vessel when;

$$
\begin{gathered}
Z=-D \\
P_{D 3}=\rho g \zeta_{a} \mathrm{e}^{-k D} \sin (k x-\omega t) \\
\dot{U}_{z}=-\zeta_{a} \omega^{2} \mathrm{e}^{-k D} \sin (k x-\omega t) \\
d F_{H}=d F_{A 3}+d F_{A 3}=P_{D 3} B d x+A_{33}^{(2 D)} \dot{U}_{z} \\
d F_{H}=\rho g \zeta_{a} \mathrm{e}^{-k D} \sin (k x-\omega t) B d x-A_{33}^{(2 D)} \zeta_{a} \omega^{2} \mathrm{e}^{-k D} \sin (k x-\omega t) \\
F_{H}=\left[\rho g B \zeta_{a} \omega^{2} \mathrm{e}^{-k D}-A_{33} \zeta_{a} \omega^{2} \mathrm{e}^{-k D}\right] \int_{-L / 2}^{L / 2} \sin (k x-\omega t) \mathrm{d} x \\
F_{H}=-\rho g \zeta_{a} \mathrm{e}^{-k D}\left[\frac{B \lambda}{\pi}-C_{m 3} \pi\left(\frac{B}{2}\right)^{2}\right]\left(\mathrm{e}^{-\frac{2 \pi D}{\lambda}}\right) \sin \left(\frac{\pi L}{\lambda}\right) \sin (\omega t)
\end{gathered}
$$

That is

$$
\begin{gathered}
F_{H}=F_{3}=F_{3 a} \sin (\omega t) \\
F_{3 a}=\left|\rho g \zeta_{a} A_{3}\right|
\end{gathered}
$$




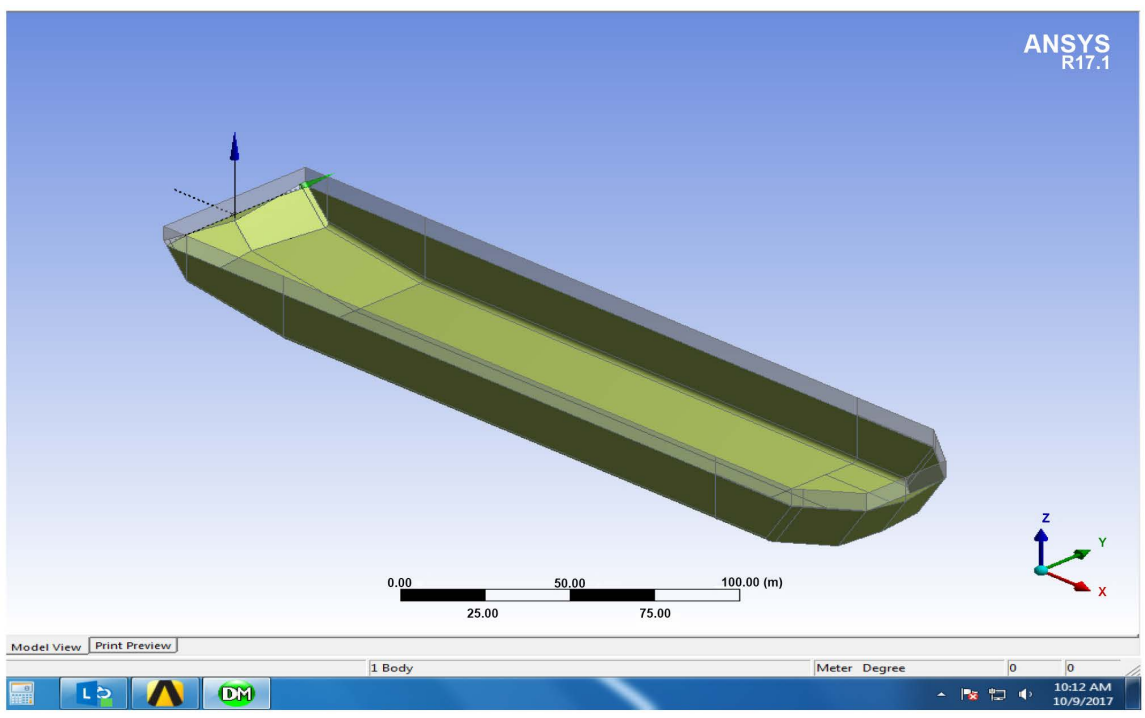

Figure 8. The FPSO unit with wave diffraction and direction.

$$
\begin{gathered}
A_{3}=\left[\left(\frac{B \lambda}{\pi}\right)-C_{m 3} \pi\left(\frac{B}{2}\right)^{2}\right]\left(\mathrm{e}^{-\frac{2 \pi D}{\lambda}}\right) \sin \left(\frac{\pi L}{\lambda}\right) \\
\left|F_{q 3}\right|=\left|\frac{F_{3 a}}{C_{33 \zeta_{a}}}\right|=\left|\frac{\rho g A_{3}}{C_{33}}\right|
\end{gathered}
$$

Therefore, the heave response amplitude operator can be written as;

$$
\begin{gathered}
R A O_{3}=\left|F_{q 3}\right| \chi Q_{3} \\
Q_{3}=\frac{1}{\sqrt{\left(1-R_{3}^{2}\right)^{2}+\left(2 d_{3} R_{3}\right)^{2}}} \\
R_{3}=\frac{\omega}{\omega_{R}} \\
\omega_{R}=\sqrt{\frac{C_{33}}{M+A_{33}}}
\end{gathered}
$$

where $Q_{3} \rightarrow$ the heave dynamic amplitude factor;

$R_{3} \rightarrow$ the frequency ratio;

$\omega_{R} \rightarrow$ the Natural frequency.

Figure 9 shows the flowchart for the MATLAB program source code.

\section{Results and Discussion}

\subsection{RAO for Surge Motion}

Figure 10 displays the RAO determined for different angle of encounter-frequency. From the results, it can be seen that the maximum RAO occurs at encounter-angle of $180^{\circ}$ which corresponds to Head sea as it increases significantly at wave period from zero and tends to maintain a constant peak value of one as the wave period increases. This implies that the maximum disturbance in the surge 


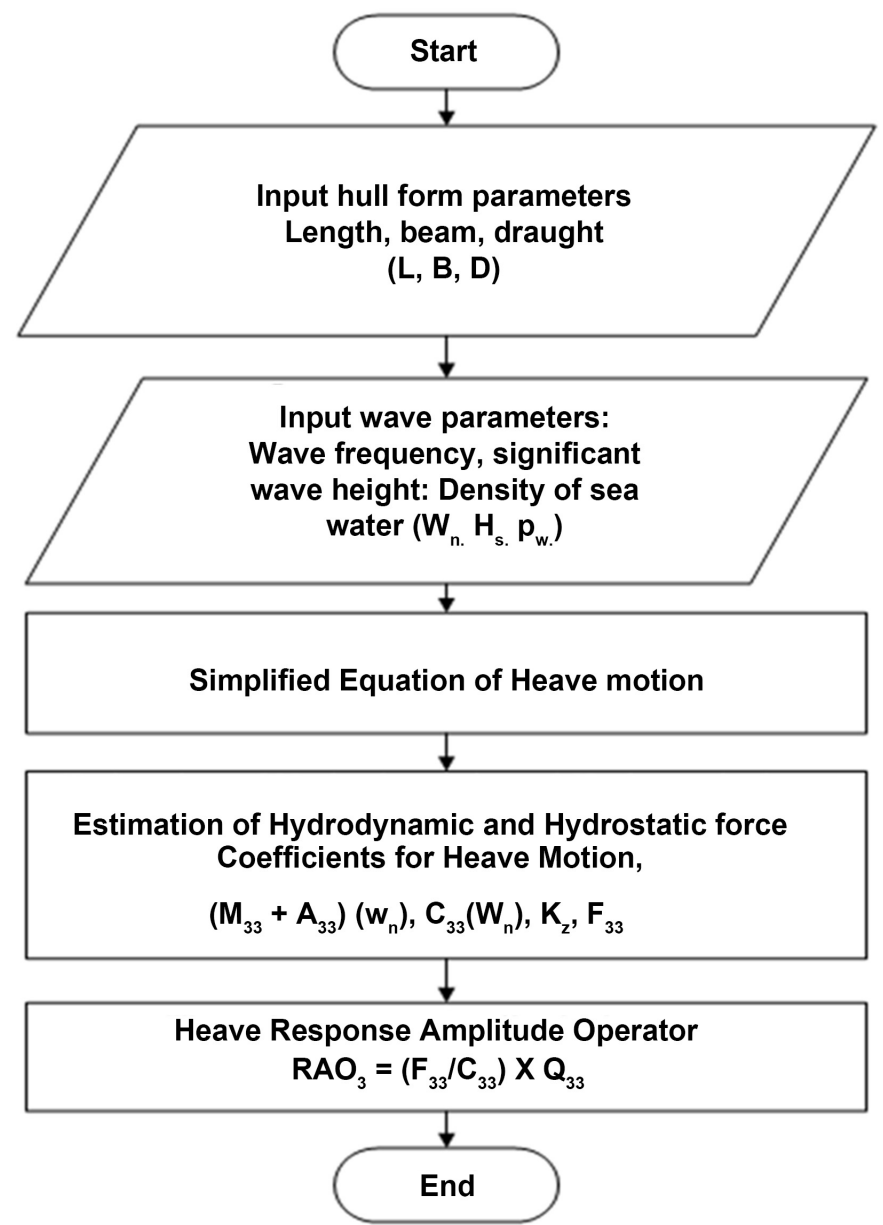

Figure 9. Flowchart for the determination of RAO for the FPSO heave motion.

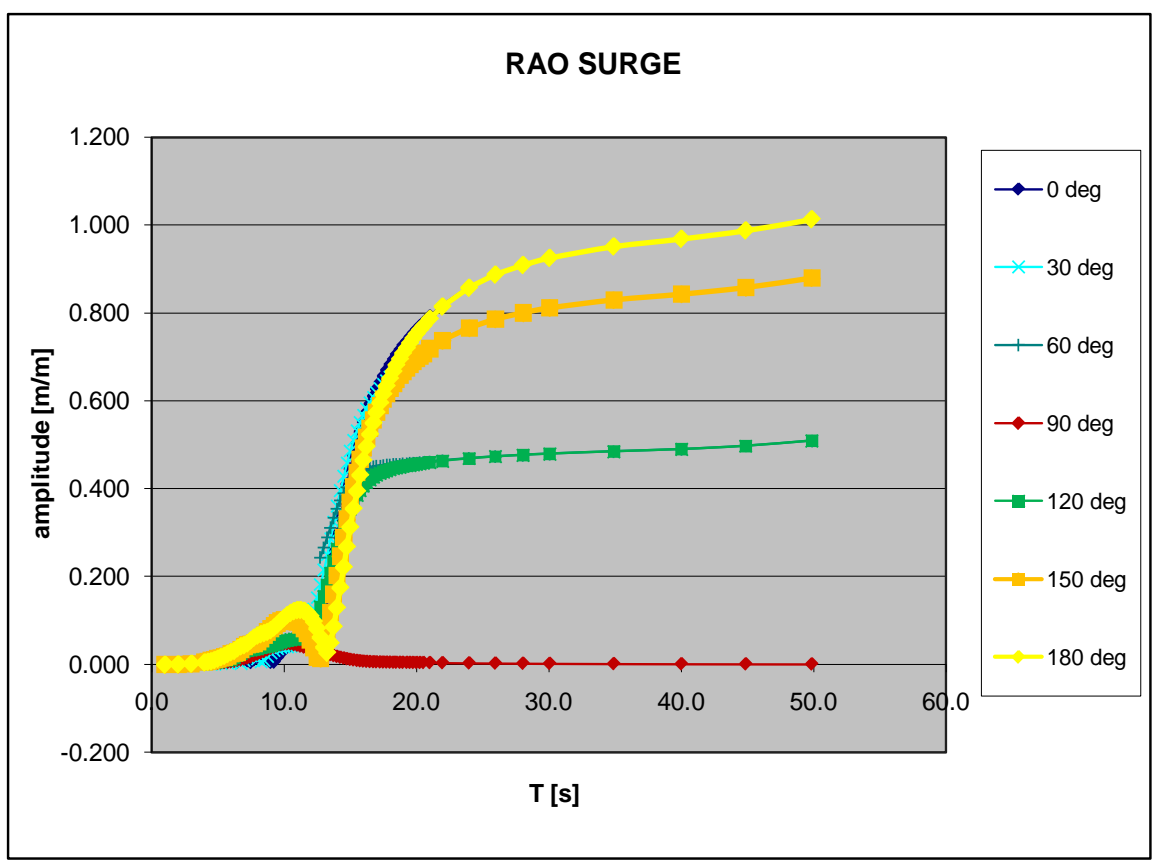

Figure 10. Surge RAO for FPSO. 
motion is experienced in the Head sea. The Surge has natural periods within the range of periods plotted and will have resonance only in low wave periods. The value of sway is not big. Small keels on the hull will reduce the sway.

\subsection{RAO for Sway Motion}

Similarly, Figure 11 shows the RAO for the sway motion of the vessel. The predominant peak value for sway response occurs at beam sea as it increases significantly at wave period from zero and tends to maintenance a constant peak value of one as the wave period increases. However, the value of sway is not big. Small keels on the hull will reduce the sway. The sway motion impacts more on the ship-handling quality than the stability. The surge and sway motion RAOs show similar trends as can be seen from the comparison of Figure 10 and Figure 11.

\subsection{RAO for Heave Motion}

Figure 12 presents the RAO of the FPSO in Heave for different angles of encounter of the wave. The heave is reasonably well behaved and increases from zero at short periods to one in long periods. The heave has natural period within the range of periods plotted and could have resonance only in low wave periods. The value of the heave translation in $100 \mathrm{yr}$ return-period is in absolute response of $1.25 \mathrm{~m}$. This means that the acceleration will not cause high seasickness for the FPSO crew. However, the data from the analysis suggests a tendency for the peak value to move to slightly higher dimensionless encounter-frequency as the sea moves from the head sea to beam sea direction.

\subsection{RAO for Roll Motion}

The roll motion in beam sea are the most dangerous inclination. In Figure 13,

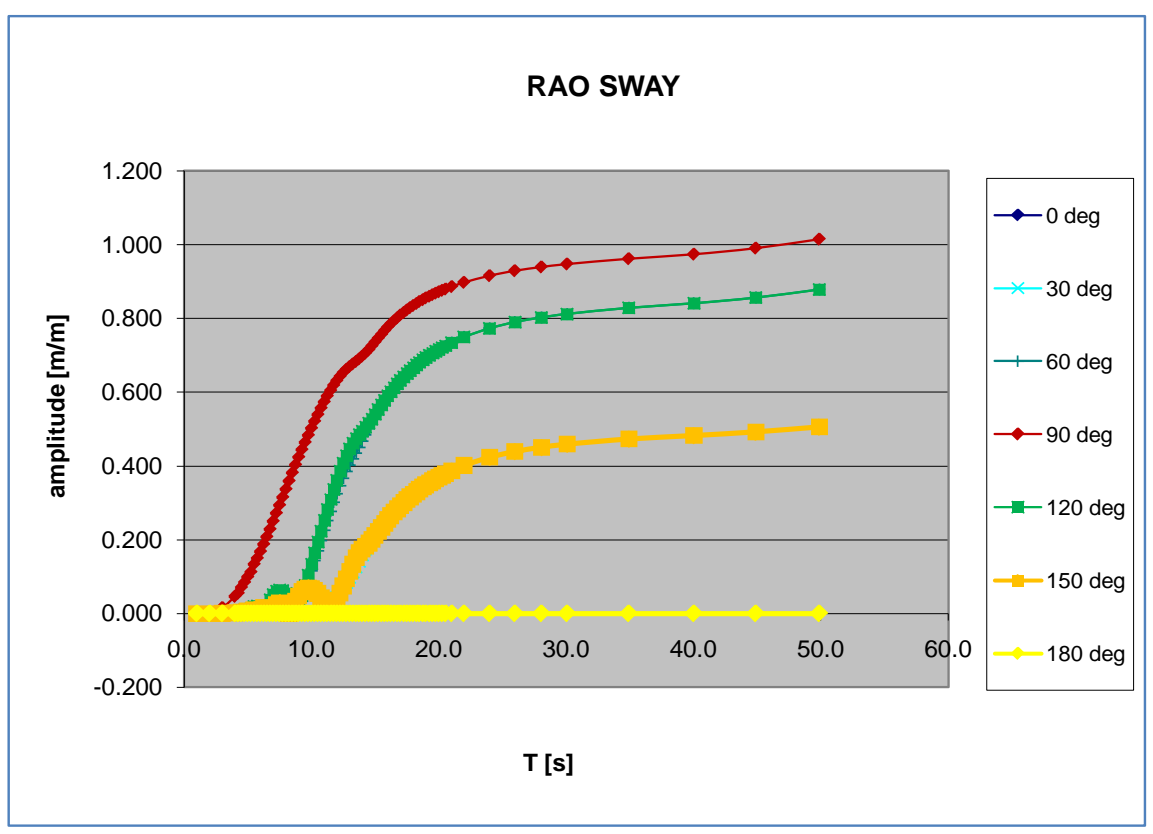

Figure 11. Sway RAO for FPSO. 


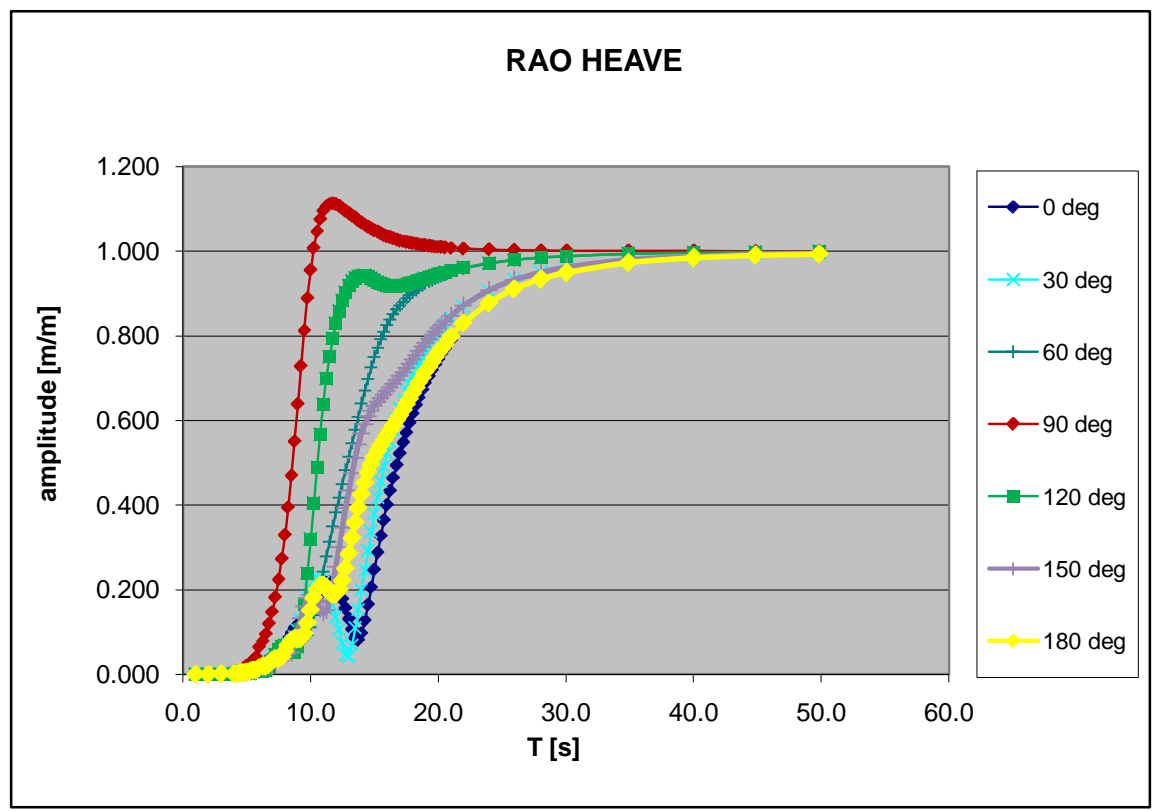

Figure 12. Heave RAO for FPSO.

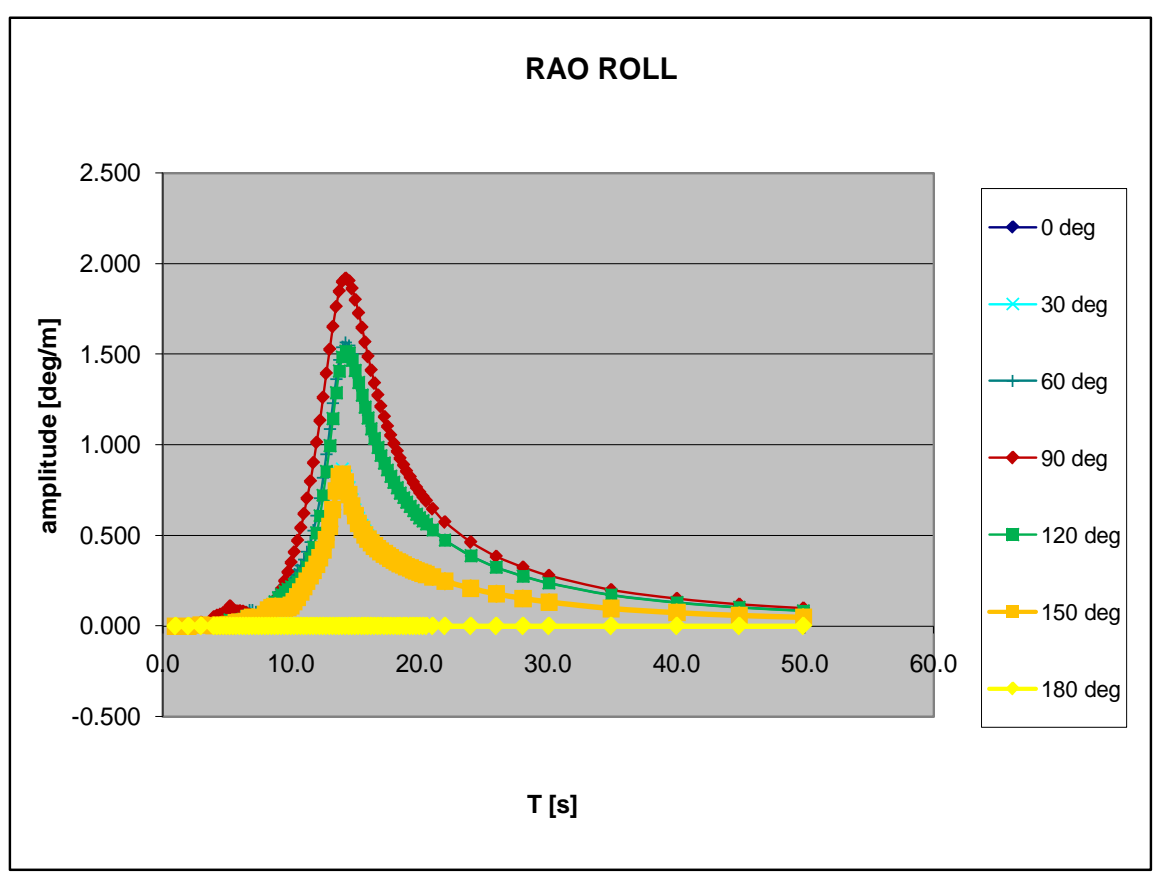

Figure 13. Roll RAO for FPSO.

the maximum value RAO is observed in the Roll motion. From the stability result of the FPSO, any value of well over $2.0 \mathrm{deg} / \mathrm{m}$ of Roll RAO can cause insignificant change in the vessel stability. For a RAO less than 2.0 the angle of inclination to $1 \mathrm{~m}$ of wave amplitude is not too much. It means that in a wave with height $2.5 \mathrm{~m}$, the FPSO inclines to $2 \times 2.5 / 2=2.5$ angle of inclination. It is not too much, and the FPSO is stable. However, it is not the operational conditions. The best solution is probably to stay in mooring position and take maximum 
possible ballast. Here again the period of resonance is the same, but with different values. The results are more regular due to large amount of data available.

\subsection{RAO for Pitch Motion}

The pitch response amplitude operator also shows significant increase in quartering seas. In Figure 14, the inclination is less than equal to 1.1 degree of one wave amplitude. It means that the bow raises to around $1.38 \mathrm{~m}$ or the sterns goes down to $1.38 \mathrm{~m}$. That is, the minimum freeboard is $31-23.03=8.47 \mathrm{~m}$ when the FPSO is fully loaded. Hence, the freeboard when the FPSO has maximum pitch inclination would be $7.09 \mathrm{~m}$.

\subsection{RAO for Yaw}

Figure 15 shows the motion response amplitude for Yaw. The peak value approaches $0.180 \mathrm{deg} / \mathrm{m}$, and this occurs at quartering sea from the Bow. As the wave period increases, there is a significant reduction of the response. The particular sea conditions encountered results in considerable variation in the amount of data collected and processed. The RAO computed shows the least value as compared to other motion of the vessel. This is true because it is more difficult for the wave energy to rotate the FPSO about the vertical axis of the vessel than other axes. This statement is also true considering the angle of encounter of the wave.

\subsection{Heave RAO from the Simplified Method with MATLAB}

In order to validate the results obtained in ANSYS AQWA for the Heave RAO in Head Sea a simplified method is developed in this work. The simplified virtual

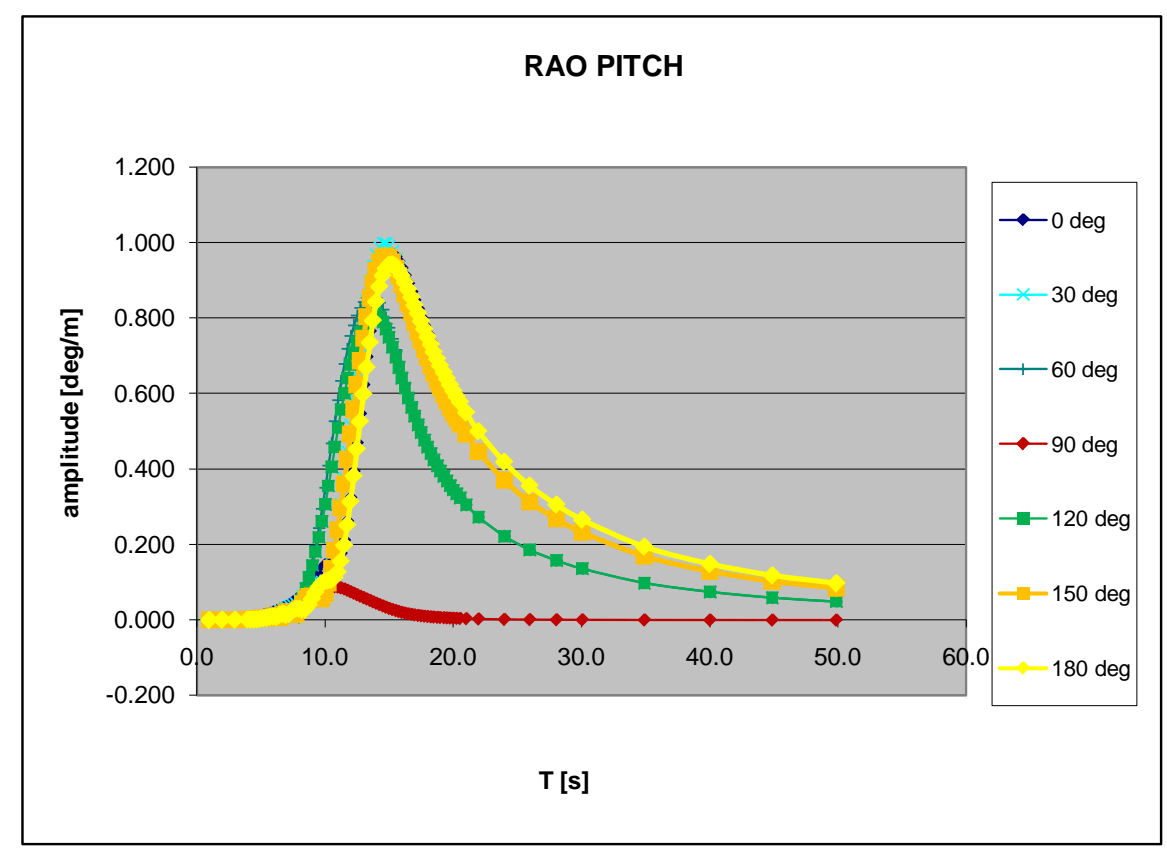

Figure 14. Pitch RAO for FPSO. 


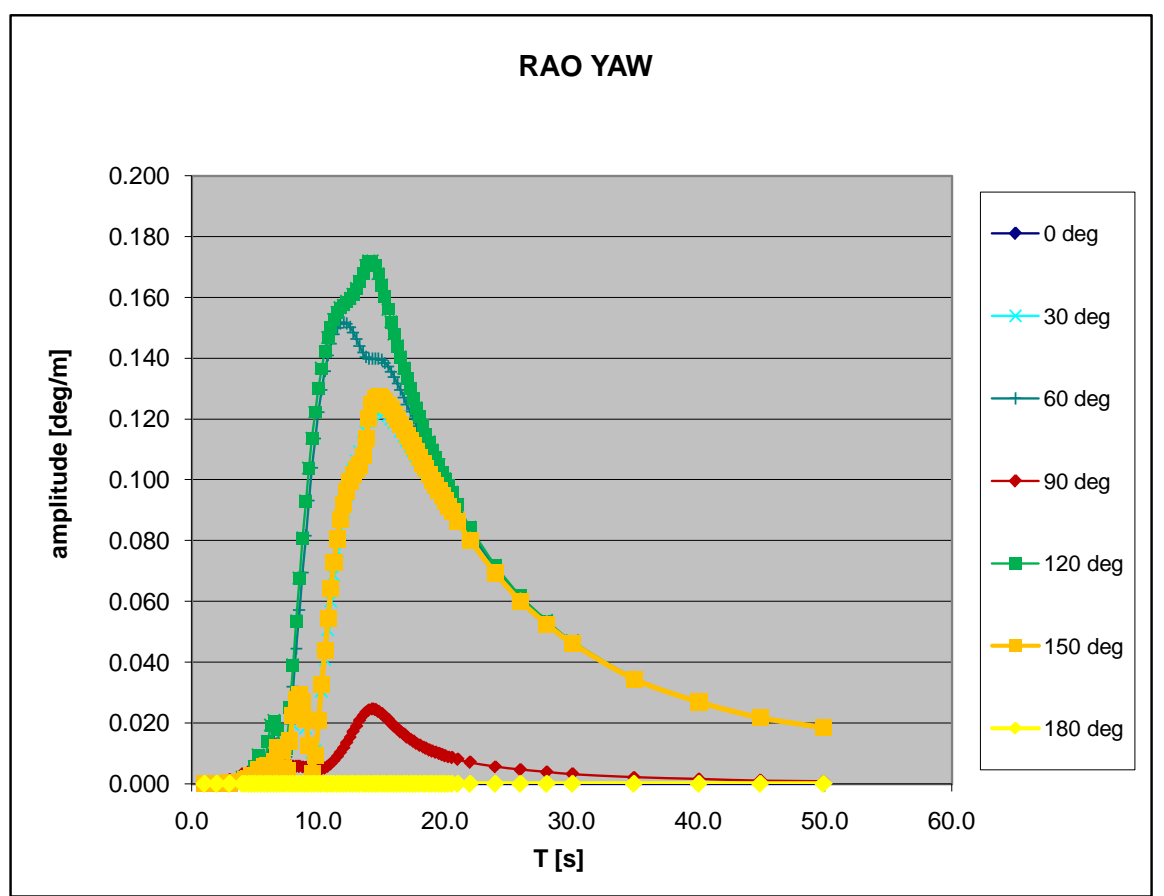

Figure 15. Yaw RAO for FPSO.

predictor, in MATLAB source code, is implemented for the Heave RAO in Head Sea. The results obtained from the program is imported to excel and plotted against those obtained from ANSYS AQWA. Since different programs use different theories, the output results are slightly different. The differences in output is not due to the hydrodynamic theory but due to overly simplified assumptions and modelling errors.

\subsection{Validation of Results}

The MATLAB program developed in this work for the determination of the Heave RAO in Head Sea is validated by ANSYS AQWA as the FPSO responds to a sinusoidal wave. Figure 16 shows the comparison of Heave RAO from MATLAB program to that from ANSYS AQWA for the FPSO in Head Sea. Predictions by MATLAB source code agree reasonably well with those of ANSYS AQWA. This implies that the developed model has the capability of predicting the RAO of heave in head seas, especially at low frequencies.

Even though the difference in predicted heave motion is small, it is necessary to note that the comparison between the MATLAB program and ANSYS AQWA results demonstrate a good agreement. Also, it should be noted that computational results depend on accurate structural description of the FPSO particulars, wave loads, and the accuracy of the MATLAB program.

\section{Conclusions}

The Response Amplitude Operator(s) of an FPSO unit is characterized using ANSYS AQWA hydrodynamic model. The RAOs are obtained for the six degrees 


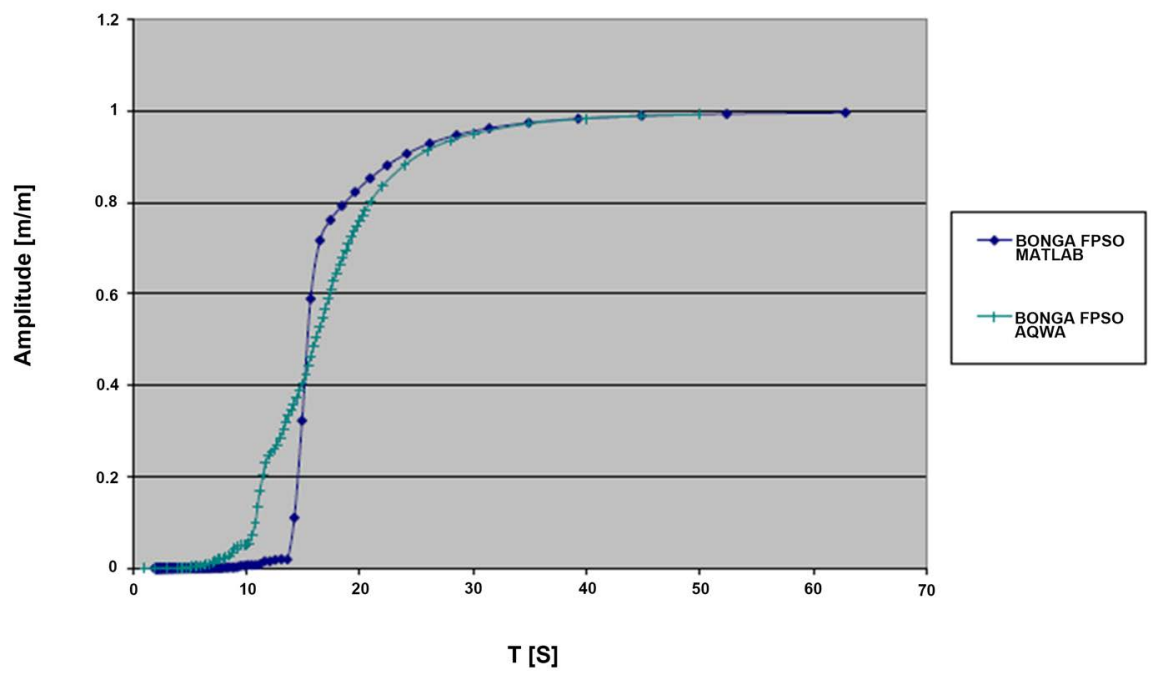

Figure 16. Comparison of MATLAB and ANSYS AQWA heave response amplitude operators for floating production storage offloading unit at head sea.

of motion. Also, a MATLAB source code is developed based on strip theory and validated via ANSYS AQWA, for heave response in Head Seas.

From the results, the maximum RAO occurs at encounter-angle of $180^{\circ}$ which corresponds to head sea. This indicates that maximum disturbance due to surge motion can be experienced in the head sea, and could have resonance only in low wave periods. The value of sway is typically small and can be further reduced by hull keels. The surge and sway motion RAOs show similar trends. Like surge, resonance due to heave occurs only in low wave periods. Also, the analysis indicates a tendency for the heave peak value to move to slightly higher dimensionless encounter-frequency as the wave moves from the head sea to beam sea direction. FPSO stability is adversely affected when Roll RAO value is well over 2.0 $\mathrm{deg} / \mathrm{m}$. In such instance, it is best to stay in mooring position and take maximum possible ballast. RAO of yaw becomes high only in quartering sea from the bow, but reduces with increasing wave period. Although a small difference in predicted heave motion occurred, it is pertinent to note that the comparison between the MATLAB program and ANSYS AQWA showed a reasonably good agreement.

\section{Acknowledgements}

The authors wish to express their gratitude to the Centre of Excellence, Rivers State University, Port Harcourt, Nigeria for providing enabling environment for the success of this research work. Many thanks to Mr. Anietie Udo for his contribution towards the publication of this paper.

\section{Conflicts of Interest}

The authors declare no conflicts of interest regarding the publication of this paper. 


\section{References}

[1] Journée, J.M.J. and Massie, W.W. (2001) Offshore Hydromechanics. Delft University of Technology, Delft, Netherlands.

[2] Lee, C.H. and Newman, J.N. (2006) WAMIT User Manual, Versions 6.4, 6.4PC, 6.3S, 6.3S-PC. WAMIT, Inc., Cambridge, MA, 343 p.

[3] Chen, J.P. and Zhu, D.X. (2010) Numerical Simulations of Wave-Induced Ship Motions in Regular Oblique Waves by a Time Domain Panel Method. Journal of Hydrodynamics, 22, 408-415. https://doi.org/10.1016/S1001-6058(09)60230-4

[4] Das, S.N. Shiraishi, S. and Das, S.K. (2010) Mathematical Modelling of Sway, Roll and Yaw Motions. Order Wise Analysis to Determine Coupled Characteristics and Numerical Simulation for Restoring Moments Sensitivity Analysis. Acta Mechanica, 213, 305-322. https://doi.org/10.1007/s00707-009-0278-9

[5] Chen, J.P., Wei, J.F. and Zhu, D.X. (2011) Numerical Simulations of Ship Motions in Long-Crested and Short-Crested Irregular Waves by a 3D Time Domain Method. Journal of Hydrodynamics, 22, 373-380. https://doi.org/10.1016/S1001-6058(09)60067-6

[6] ANSYS $^{\circledast}$ AQWA $^{\mathrm{Tm}} 13.0$ (2010) Design Manual. http://www.ansys.com/ 